\title{
Community sport and social cohesion: in search of the practical understandings of community sport practitioners in Flanders
}

\begin{abstract}
Current literature suggests that community sport contributes to social cohesion. Yet, empirical research is still scant, and existing conceptualizations of social cohesion in the context of community sport are dominated by a social capital approach emphasizing the individual over the structural conditions that need to be addressed if social cohesion is to be achieved. This article aims to provide more insight into how social cohesion is operationalized in community sport practices. Qualitative research on the practical understandings of community sport practitioners was undertaken across three cities in Flanders, Belgium. The findings suggest that practitioners adopt both individual and structural understandings of social cohesion. Moreover, they experience that their efforts to develop a structural approach are pressured by a dominant individualized approach. These findings reveal a disjuncture between academic constructs of social cohesion and the practical understandings of community sport practitioners. The article proposes ways to address the need for the empirical and conceptual development of social cohesion in the context of community sport and the broader community development field.
\end{abstract}

\section{Keywords}

Community sport, social exclusion, social cohesion, social capital

\section{Introduction}

Community sport is regularly portrayed as a cure for a plethora of problems on two levels: on an individual level, community sport enables vulnerable youth to develop life skills, competences, and character; on a community level, it contributes to the wider practice of community development and to social cohesion as an outcome of community development (Bramham, Hylton, Jackson and Nesti, 2001; Coakley, 2015). Community development can be approached in two manners. A first approach refers to community development as an ongoing process, guided by the initiatives of individuals, communities and organizations (Donnelly, 2015). A second approach perceives community development as the complex of the interventions in itself and thus refers to a wide body of practice, rather than the process or 
result of that intervention. In their research on community sport, for example, Christenson, Fendley and Robinson (1989) describe community development as 'a group of people in a locality initiating a social action process (i.e. an intervention) to change their economic, social, cultural, or environmental situation' (Schulenkorf, 2010 p. 5). Community sport in particular is perceived as a valuable intervention within community development as it enables the participation of lower socio-economic groups in the community (Schulenkorf, 2010; Skinner, Zakus and Cowell et al. 2008). Community sport has thus been promoted as a way to engage communities, and particular groups within them, such as socially vulnerable young people who may be hard to reach through other social institutions such as mainstream education, leisure time or community work (Crabbe, 2007; 2009). Community sport does so by using sport as a point of entrance. As Ekholm (2016) puts it, 'sport could be presented as an omnipotent tool for achieving social policy objectives in more or less any distinct historical or political context... with only slight variations in the momentary fixity of meaning ascribed to it' (p. 11). Simultaneously, however, community sport responds to the perceived inadequacy in regular sport formats to break 'hierarchies present in society as a whole' (Sabirova and Zinoviev, 2016, p. 482). Drawing upon its roots in the practice of community development, community sport engages itself with issues of power and inequality and strives for social change (Goldsworthy, 2002). As such, within the literature, community sport is described as one possible intervention within the broader field of community development practices known as community development.

A basic presumption with regard to community sport is that it can help to establish social cohesion (Coakley, 2011; 2015); a concept which is deeply embedded in community development theory and practice (e.g. Philips and Berman, 2003; Smets, 2005). This idea is based on the assumption that there is a lack of cohesion within the community (Spaaij et al., 2014; Stead, 2017). However, such claims are founded upon concepts of social cohesion that are largely theoretical and not based on empirical research. Furthermore, conceptualizations of social cohesion within the context of community sport are largely confined to a social capital approach in which social capital is perceived as an individual property and through which structural issues such as community equity are left disregarded (Crabbe, 2009; Ekholm, 2016; Kelly, 2010; Vandermeerschen, 2016).

Therefore, in our research, we have approached the Flemish community sport field as a 'reflective practice' (Ruch, 2005, p. 171) through which we can access the everyday theorizing of practitioners with regard to how they understand social cohesion and how they 
see their practices contributing to it. We elicit this knowledge through a qualitative study of three practices of community sport in Flanders, the Dutch-speaking part of Belgium.

This article is structured in three sections. The first section critically examines the concept of social cohesion, the second describes the research method and context of Flanders, and the third discusses the findings of this research.

\section{Social cohesion: a conceptual quagmire?}

Several studies have considered how community sport contributes to social cohesion (see for example Kelly, 2010). While some studies have undertaken empirical research (e.g. Meir and Fletcher, 2017), explicit evidence of how sport contributes to social cohesion in community contexts remains limited (Beutler, 2008). Stead (2017) argues that this absence is due to the fact that 'relatively little attention has been paid to the on-the-ground-dimension, of its emergence, to the local places where these translations occur' (p. 4). This suggests that little is known about how specific communities translate general notions of social cohesion to local realities and aspirations. Existing research addresses social cohesion as an abstract concept, implying that it is generally applicable to all contexts. According to Reeskens (2008) 'nobody seems to have a clue what [social cohesion] actually means' (p. 2). However, the multiplicity of interpretations is overshadowed by a dominant conceptualization of social cohesion as equivalent to social capital. Two influential conceptualizations of social capital are that of Putnam (1993) and Bourdieu (1986). Putnam (1993) refers to social capital as 'features of social organization, such as trust, norms, networks that can improve the efficiency of society by facilitating coordinated actions' (p. 167). In particular, Putnam (1993) draws upon the importance of these networks in the form of voluntary organizations, such as sport clubs. Bringing people together in these cooperative activities might strengthen the bond between people and become a source of trust (Glover and Hemingway, 2005). In contrast, Bourdieu (1986) offers a broader conceptualization of social capital, which is embedded in his analysis of the role of social structures in reproducing social power and inequalities. According to him, social capital is part of a range of social, cultural and economic resources that individuals and groups can accrue, use, or convert to enhance or preserve their social position.

The notion of social capital, and particularly Putnam's approach, has received considerable attention in community development (Kay, 2005). It has been argued that social capital is a necessary ingredient for the practice of community development as it provides social linkages between people and therefore can contribute to the 'increase[d] access to 
recourses outside the community' (Dale and Newman, 2008, p. 5). Voluntary and community organizations, such as community sports (Schulenkorf, 2010), are perceived as providers or facilitators of this web of social networks (Kay, 2005). Social capital is often perceived as a precondition for achieving social cohesion (Berger-Schmitt, 2000). However, some scholars have criticized this reduction of social cohesion to the mere domain of social capital (Skinner et al., 2008). They argue that this might lead to providing mere 'tools and training that enhance individual productivity' (Markus and Kirpitchenko, 2007, p. 27). Notwithstanding the fact that the Bourdieuan approach to social capital provides a rather broad understanding of capital (which also includes cultural and economic capital), both Putnam's and Bourdieu's conceptualizations point at social capital as an individual property rather than a property of the community. In relation to community development practice, it is argued that social capital in itself is insufficient to develop communities (Dale and Newman, 2008) as long as they are not used for the establishment of a balanced and equitable society (Kay, 2005).

In light of this critical perspective, community sport in particular is seen as a field of practice that is liable to this threat of reducing the maintenance of social cohesion to the establishment of social capital (Ekholm, 2016; Spaaij, 2011). Scholars within the community sport field have particularly critiqued this reduction as it tends to exclude structural dimensions of social cohesion, such as social equality, equity, and solidarity (Ekholm, 2016). The absence of such a structural perspective can lead to a decontextualized analysis of the complex reality of socially vulnerable youth (Vandermeerschen, 2016). This is problematic as it foregrounds and privileges individual deficits over structural inequalities that shape the experiences of those who are excluded from communities or who are from excluded communities (Kelly, 2010), and thus renders community sport incapable of contributing to the meaningful development of the community (Dale and Newman, 2008; Kay, 2005).

Despite this critical perspective, less reductive understandings of social cohesion can be found on a conceptual level (see for example Kearns and Forrest, 2000), in which social cohesion is described as an asset of the community rather than an individual property or resource. An interesting framework in this regard is offered by Markus (2016), who views social cohesion as comprising five dimensions: (I) belonging, (II) participation, (III) acceptance, rejection and legitimacy, (IV) worth and (V) social justice and equity. Belonging, the first dimension, refers to shared values, trust, and identification with the country of residence. The second dimension focuses on the degree of political participation, voluntary work, and co-operative involvement. The third dimension refers to experiences of discrimination and attitudes 
towards minorities and newcomers on a neighborhood level. The fourth dimension addresses life satisfaction, happiness and future expectations. The fifth, and last, dimension draws upon the issue of social justice and equity, indicating the extent to which national policies create economic opportunities. Whereas the dimensions of belonging and worth seem to refer primarily to individual resources, similar to Putnam's social capital theory (such as a sense of belonging, sense of pride, financial satisfaction, general happiness), the framework also contains structural components of social cohesion, particularly in the remaining three dimensions of 'participation', 'acceptance, rejection, legitimacy' and 'social justice and equity'. Within these three dimensions, Markus (2016) draws attention to structural issues such as the (unequal) distribution of economic goods and opportunities - which he defines as government intervention towards economic redistribution (e.g. financial support for people on low incomes), political participation, discrimination and acceptance of minority ethnic groups. However, scholars argue that this kind of multi-dimensional approach is largely absent from understandings of social cohesion in the context of community sport as attention is rarely given to the structural causes of inequality, such as social division and power inequality (Crabbe, 2009; Spaaij, 2011).

\section{Methodology}

A qualitative study of the practical understandings of social cohesion within practices of community sport was undertaken in Flanders. Flanders has been promoting a sport-for-all policy for the past forty years and has been described as 'one of the pioneers in implementing the first European Sport-for-all Charter' (Theeboom et al., 2010, p. 1393). Moreover, community sport has been the most frequently used approach to achieve this objective of sport-for-all in Flanders (Theeboom and Haudenhuyse, 2015). Interventions using the practice of community sport have occurred in cities with culturally diverse populations, high poverty rates, and included a number of vulnerable neighborhoods, i.e. high numbers of single-parent families, children in special education, unstable accommodation and low employability (Province of West Flanders, 2014).

The research was conducted in the cities of Brugge, Kortrijk, and Ronse. Three organizations supervise the practices of community sport in the selected cities. In Brugge, community sport intervenes in four neighborhoods under the supervision of the Public Centre for Social Welfare. In Ronse, community sport is organized by the local government in three 
vulnerable neighborhoods, and in Kortrijk, it operates in four neighborhoods through the nonprofit organization AJKO, situated in the youth and welfare sector.

\section{Data collection and analysis}

During 2016, the first author conducted thirty-four semi-structured interviews with practitioners, partners, and key figures (financial stakeholders and ex-practitioners). Purposeful sampling was used to maximize the richness of the data (DiCicco-Bloom and Crabtree, 2006). Out of the 18 community sport organizations that expressed interest in the research project, the practices in Brugge, Kortrijk and Ronse were selected according to two criteria: (I) their approach (mission, vision, goal setting) and the content (organization of activities) of their practice as they specifically relate to social cohesion, and (II) the factors that influenced their selection of the community, such as the size of the city, the size of the setting, organizational structure, geographical spread, and target group.

We selected 16 practitioners, 17 local partners and one ex-practitioner across the three practices based on their knowledge and experience. Of the 34 respondents, 19 were male and 15 were female. Thirteen respondents were aged from 21 to 30. Fifteen respondents were aged between 31 and 40. Five respondents were aged between 41-50 and one respondent was older than 50. Twenty respondents had between one and ten years of professional experience in community sport or a related sector (youth, welfare, community and/or sport). Ten respondents had between 11 and 20 years of working experience. For four partners this information was missing. The profiles of the practitioners across the three practices ranged from coordinators to coaches employed through the local service economy and voluntary staff.

During the interviews, we asked the respondents four main questions: (I) What are you seeking to achieve when taking social cohesion as an objective of community sport? (II) What are the expected effects of the establishment of social cohesion and why is it important to strive towards these effects? (III) How and to what extent does community sport currently contribute to social cohesion? And (IV) which mechanisms and conditions influence this contribution to social cohesion? Three focus groups (with 11, 12 and 9 participants, respectively) were held in 2017 with practitioners from the broader community sporting field in Flanders to gain a deeper understanding of the collective construction of meaning with regard to social cohesion. During the focus groups, the respondents were asked about the tensions, ambiguities, and conflicting understandings expressed within the interview data. 
All interviews and focus groups were audiotaped and transcribed verbatim. A conventional content analysis (Hsieh and Shannon, 2005) was applied to analyze the transcripts. This process was largely inductive as we allowed the codes and categories to emerge from the data, rather than assign preconceived categories. Using a coding tree, the data was sorted into categories. The researcher reviewed the categories for areas of overlap and searched for relationships between categories (Westbrook, 1994). Clusters of categories or themes where derived from the data. Furthermore, fifteen percent of the transcripts were analyzed by two other senior researchers in order to enlarge the credibility of the data analysis and interpretation. The ethics commission of the Faculty formally approved this study.

\section{Findings}

Our analysis showed that practitioners referred to both individual and structural understandings of social cohesion. They pinpointed the individual understanding as a dominant one in their practices and revealed tensions between both understandings. In the next section, we present our findings with regard to these practical understandings of social cohesion, as well as the respective implications for the day-to-day practice of community sport and the relationship between both. Both understandings are illustrated with quotations from the interviews (I) and focus groups (FG).

\section{'Awarding responsibility': a dominant understanding}

A first practical understanding implied the establishment of social cohesion by enhancing participants' 'local grounding' (I7). Practitioners argued that within community sport, there is a strong belief in the effectiveness of building young people's competences, skills and attitudes as this helps them to uplift themselves from their deprived living circumstances. In other words, this notion of local grounding referred to the conviction of practitioners that participants can transcend their living circumstances, as long as they continuously engage themselves in activities, which could enhance their entrepreneurship, ownership and responsibility. During the interviews, practitioners stressed the importance of enhancing responsibility as a way to establish or regenerate young people's social status. Moreover, the analysis showed that this understanding of social cohesion was dominant in the thinking and acting of practitioners and the community sport sector in general. Concretely, taking up more responsibility implied that participants were expected to engage themselves in a meaningful role within the community (e.g. through obtaining some form of employment, or voluntary 
work): 'they are often people who don't work, who are unemployed, who sit at home, for all sorts of reasons and who we try to give a role. Favorably it's a role in which they can move towards taking up more responsibility' (FG2).

The data, moreover, revealed how practitioners framed the importance of responsiblizing vulnerable young people within the broader necessity of enhancing participants' feelings of belonging to their neighbourhood. Practitioners argued that, in order for participants to take up a meaningful role in their community, feeling 'proud of the role they fulfil in their own lifeworld' (I7) and experiencing that they are 'needed in the community' (FG1), is essential. Participants gave us particular insights into their day-to-day practice and how it sought to enhance young people's feelings of belonging and, relatedly, their sense of responsibility. In what follows, we draw upon three particular actions.

First, practitioners attempt to enhance participants' feelings of belonging to their neighbourhood, by creating 'small encounters' (I24) between participants, characterized by gestures of greeting or saluting, and thus not necessarily by enhancing 'strong ties' (I23) which are defined by deep intimate conversations. As such, practitioners stated that they strongly believe in the vigour of small encounters, in which the possible interrelations and connections between participants are open-ended, rather than predefined. Furthermore, practitioners considered the potential of these small encounters as a way to "make strangers acquainted' (I23), or as one respondent argued: 'even though they have not talked to each other or maybe they only heard each other's names through the microphone, they are not complete strangers anymore' (I23).

Second and building upon this first action our analysis showed how practitioners do not merely enable encounters between participants, but also seek to address the perceived disconnection between participants and the wider community. Practitioners do so by welcoming local residents into the community sport site (e.g. through organizing play-dates between parents and participants or by engaging community residents as supporters during competition). Moreover, practitioners undertake efforts to step outside the traditional sport site into public space (seen here as the sphere between the community and the state wherein interactions among strangers and intra-group relations could occur through open and inclusive participation, (see for example O'Carroll, 2002; Grodach, 2009; Kay, 2005). Practitioners support this movement towards action in public spaces (e.g. by engaging passers-by during a game of grandmother's footsteps in a shopping street), as they work to enhance the wider public's recognition of participants as active members of society. Practitioners thus stressed 
that these feelings of belonging (through becoming contributing citizens in society), are not only attained as an internal process through the competences of participants, but are also promoted externally, through the positive acknowledgement and affirmation of community residents.

Furthermore, practitioners aim to influence the positive recognition of participants, as they are often stigmatized by the wider public. Practitioners attempt to do so through enhancing the positive branding of the community sport organization as a meaningful actor within the community and thus by making the results of their efforts visible to residents (e.g. through a talent show or an exhibition). By identifying the participants as part of the community sport organization (e.g. through the use of logos, t-shirts, flags, and other visual expressions of the organizational identity), practitioners try to transfer the constructive image of the organization to that of participants. One respondent emphasized: 'people see everything. Moreover, they see that we are doing a great job. It makes them realize that these youngsters can be trusted' (I17). In essence, this does not imply that community sport by definition changes the behavior of participants towards what is socially desirable, but rather that their positive attitudes are more easily recognized within the wider community.

Finally, the engagement of community sport within public spaces provides particular challenges, which practitioners try to act upon in particular ways. The respondents argued that the nature of the public spaces in which they engage themselves is contested. Whereas community sport participants are eager to 'explore a world outside their own backyard' (I7), they were simultaneously subjected to a social disorder discourse - given form by residents, social and civil services - which often resulted in their exclusion from these public spaces. Practitioners expressed their belief that participants could rise above this discourse and exclusion. In particular, participants were urged to negotiate within the discussions on public spaces and to promote the idea of public space as a place to explore, play and encounter. Here again, practitioners put the responsibility of participants forward as an answer to a much wider inducement, namely the access of vulnerable young people to publicly owned spaces.

The above-mentioned three practical actions all relate to an understanding of social cohesion in which young people are stimulated to take more responsibility in their own lifeworld. As one respondent argued "what is really important is the trajectory we take up with young people in which they evolve from being a participant to becoming the main drive of the initiative' (I1). Thus, by providing a 'platform in which people can optimally use their talents 
and strengths' (FG2), practitioners aim to create a shift in which participants can take over responsibility from practitioners and wherein community sport makes itself redundant:

A clear objective of our project is that the participants further the programme autonomously. We would love to see ourselves as dispensable for the existence of the project in a few years from now. We strive from the local grounding of the organization in the wider community, so that participants can totally control and exploit the project themselves. (FG2)

\section{'Changing life conditions': tensions and pressures}

Notwithstanding the fact that practitioners recognized the individual understanding of social cohesion as a dominant part of their day-to-day practice, practitioners simultaneously gave notice to the tension this dominant understanding provides with rather structural ways of comprehending and striving for social cohesion. This tension was reflected in the data through two specific and consecutive critiques of practitioners.

Practitioners stressed that enhancing the responsibility of socially vulnerable young people is beneficial for their development. As such, practitioners saw no harm in promoting self-responsibility. However, they did problematize the way in which responsibility is understood and measured by local policy, namely as a fixed concept using pre-structured indicators (e.g. attendance of all activities) as well as the way local policy imposes this approach on community sport organizations.

I mean, you can't expect them to be there every week. If a girl of 12 years old, who's been responsible her entire life for her family because her mom is single and works around the clock to provide for her family - if these girls are responsible for their brothers and sisters all day, you can't expect them to be here every Wednesday afternoon. Even if that means that the project doesn't run smoothly because of that. (I1)

In other words, within the rather individual understanding of social cohesion, participants could be condemned for not taking responsibility at the time, in the places, in the way practitioners or policy makers want them to, whilst they are possibly taking huge amounts of responsibility in other life domains. Furthermore, this governing of vulnerable young people might fuel a culpabilizing approach in which youngsters are blamed for failing to take responsibility without questioning possible reasons for this 'lack' of responsibility.

Aligning with this first critique, practitioners stated that enlarging young people's responsibility did not necessarily ameliorate the life conditions of participants. As one 
respondent argued: 'Sure, the things participants do here refer to being more independent and being more responsible. However, they all remain uneducated, without any degree. Eventually they will end up in low-wage jobs in which they are expected to do their job and keep their mouth shut' (I19).

Sprouted from this critique, practitioners urged for an alternative understanding in which establishing social cohesion refers to structural changes in the life circumstances of vulnerable young people, with the ultimate objective of creating a balanced and equitable society. Practitioners elaborated on this by stating that structural inequality is the main legitimation for community sport to intervene in young people's leisure time. In the words of a respondent: 'We really strive to change something about their situation. I think this should be the starting point. Moreover, there should be a rock-solid belief that we can do so' (I12).

Notwithstanding the fact that practitioners urged the implementation of this structural understanding of social cohesion in the context of community sport, our analysis showed that this often remained a distant ambition rather than a practical approach, as practitioners experienced not much vigour to do so:

You could say we are a like a drop of water on a hot plate. The only thing we can do is distract youngsters from their situation and that is valuable as well. We do not have the ambition... or else we are not in a position to change anything and moreover we don't have the means to do so. (I11)

Practitioners gave notice to the impossibility they experienced in translating this ambition into a day-to-day approach. Furthermore, respondents felt hindered to make this translation as they experienced a tension between both understandings. This tension was pinpointed on both an external and internal level. Externally, practitioners stressed that 'policy and institutions are still a huge obstacle towards youngsters in attaining this social balance' (I2). In other words, practitioners felt pressured, particularly by local government, to conform to rather responsibilizing understandings of social cohesion. This pressure is foremost manifested in the drive towards enhancing participants' self-responsibility and the way in which responsibility is forced upon practitioners as a fixed concept, based on predetermined indicators. One respondent drew upon this tension as such:

The view of policy, namely that participants get the same opportunities as everyone else and that it is their responsibility to take those chances, is counteractive [in relation to the customized approach of 
community sport]'. It simply is untrue as well. Getting the same opportunities, sounds great right, however sometimes kids reside in life circumstances through which they cannot fully grasp those chances. (I1)

Respondents thus pinpointed the disjunction between their view on responsibility and the view of policy makers. They explained that challenging the view of local policy makers is, however difficult, as local governments are the main sponsors of community sport. As the funding of community sport practices is based on their 'success' on individual indicators (e.g. number of participants reached, duration of participation, performance rates and employment trajectories), the practitioners expressed that they eventually limit themselves to reporting about their practice in terms of these individual indicators. As a result, higher level indicators (such as social inclusion), which are more abstract, take a longer period of time to materialize and require for shared responsibilities with other organizations are left out of the picture and hence not explicitly recognized by policy makers as meaningful indicators of success. Therefore, practitioners acknowledged that, by not using structural indicators to report about their practice, they continuously confirmed, affixed and reproduced this dominant understanding and failed to impinge on it. As one respondent argued: 'There is always a major difference between what you say to sell your case, and what you actually realize' (FG1).

Building upon this further, our analysis showed that practitioners faced particular internal challenges, which might explain why they have not yet been able to break through the consolidation of this dominant understanding. Respondents argued that they often lack the experience, expertise and knowledge to find a way to translate their ambitions in their day-today practice. As one respondent argued:

If you want to change something structurally in the life circumstances of participants, you have to build bridges towards policy makers. For most of the practitioners here, especially in the beginning of their career, they are not really up for it, however, it is really important to search for ways in which they can do so. (I1)

The main issue within both the internal and external tension was that practitioners wanted to give form to social cohesion in a more socially and politically meaningful way, but they could not find the language to do so. In particular, they did not have the scope and concepts to translate this into an approach, which was feasible and attainable in the context of community sport. Neither did they have the mandate nor the place to bring this into communication with 
local policy. Notwithstanding these tensions, practitioners argued that they have to continue this distant ambition. Taking poverty reduction as an example, one respondent argued:

I'm absolutely convinced that community sport has a direct impact and structurally contributes to poverty reduction. However, the direct relationship is often hard to expose. But even if so, this takes nothing away from the firm belief that there is a relationship... the proof is in the way we keep on deploying towards this objective. (I29)

\section{Discussion}

In this article, we have drawn upon the critical literature with regard to the individualizing tendency in theoretical conceptualizations of social cohesion (in particular through the dominance of social capital theory). Furthermore, we discussed how critical scholars have argued that in its concrete practice, community sport is liable to completely withdraw itself from engaging with structural conditions (such as establishing social equality, equity and solidarity) and thus from addressing social inequalities in society as a whole. However, the contribution of community sport to social cohesion has hardly been the subject of empirical research. Based on this observation, we examined practical, on-the-ground understandings of social cohesion that are articulated and enacted by practitioners in Flanders.

Throughout the findings, we observed a clear disjunction between theoretical constructs and the practical understandings of community sport practitioners with regard to establishing social cohesion through community sport. Whereas critical scholars have stated that community sport practices apply an individual approach to social cohesion, the findings revealed how practitioners themselves adopt both individual and structural understandings of social cohesion. Within a first, rather individual understanding, practitioners referred to social cohesion as obtaining or regaining social status by taking responsibility through actively and meaningfully contributing to the respective communities of participants. Moreover, practitioners appointed the attainment of high levels of belonging as a precondition for striving for the enlarged responsibility of participants. Furthermore, this understanding results in an approach that consists of three distinct actions: (I) stimulating small encounters between community sport participants; (II) enhancing the recognition and acknowledgement of community members towards participants as active members of that community, and (III) combatting the exclusion of vulnerable young people from public spaces by appointing 
participants based on their commitment to intervene in discussions on the use of that space and to subsequently change the social disorder discourse to which they are subjected. Within a second, more structural understanding of social cohesion, practitioners stated to perceive social cohesion as the attainment of structural and durable changes in the life conditions of participants and the establishment of an equitable society. Moreover, this structural understanding was pinpointed as the main legitimation to intervene in the life worlds of participants in the first place, rather than the responsibilizing understanding.

Throughout the findings, practitioners not only shed light upon the existence of this dual understanding of social cohesion, but they also reported on the (internal as well as external) tensions between both. The participants clearly acknowledged the dominant individualized approach as an integral part of their practice, while at the same time perceive this approach as insufficient to make structural changes in the lifeworlds of participants. When the objective to attain responsibility is uncoupled from the structural life conditions of participants, it threatens to become a hollow objective, which is attained, just for the sake of it, without further ado. Practitioners therefore suggested to implement an alternative structural approach to the practice of community sport.

\section{Conclusion}

Two main conclusions can be drawn from our research. First, in contrast to the claim made in literature, our study shows that community sport practices do adopt structural notions of social cohesion. Not only do practitioners endorse structural understandings of social cohesion on a conceptual level, they continuously maintain their ambition to translate this into their actions, even when they feel pressured to do otherwise or lack the vigour to succeed in this objective. Although this observation might seem hopeful, it also shows that the structural potential of community sport to establish a suitable approach remains largely untapped. We argue that knowledge of community sport and its relation to social cohesion should also emerge from the everyday practice of practitioners. The fact that to date there has been little empirical research and situated analyses of community sport practices is a concern. If community sport is only seen as benefiting the individual, it may easily be isolated from structural debates on inequalities in society.

Second, our results highlight the challenge of practitioners to report, conceptualize and give language to structural actions that are being undertaken within their practice, how small they (yet) may be. Practitioners report that within the practice of community sport there is a 
tendency towards increasingly adopting structural approaches to social cohesion. Existing conceptual frameworks of social cohesion are insufficient to capture the complexity of community sport. This hinders practitioners to counter the dominant individualized approach, which seems more developed on a conceptual level. This tendency displays itself not only in community sport but within the broader field of community development practices, and it is intertwined with tendencies towards marketization, wherein 'programs are dropped into settings without proper need assessments in the community, through the use of off-the-shelf programs and marketing, and delivering programs in short-term episodes without ensuring that people are in agreement. That is, they often miss matters of sport sustainability and true community development' (Skinner et al., 2008, p. 270).

These conclusions underline the importance of two issues. In the first instance, shifting the theoretical understanding of practitioners can be stimulated by simply showing them how they currently do and can interact with structural issues. Second, we urge for the conceptual development of social cohesion in ways that resonate more strongly with - and are informed by - the actions and practical understandings of practitioners. We encourage community sport practices to align more explicitly with existing reflective and radical community development practices. These movements, which are focused on social change, might provide a lever for community sport to focus on 'fixing society' rather than solely 'fixing individuals' (Goldsworthy, 2002, p. 328) and could possibly contribute to breaking down the dominant individualized paradigm of social cohesion.

In order to address the need for structural understandings of social cohesion, we propose the development of a research agenda that builds upon the idea of community sport practices as reflective practices (Ruch, 2005). Such a research agenda, which holds the potential to assemble both critical enquiry and action, and can be conducted through an action research approach, might allow practices to reflect and act upon structural dimensions of social cohesion, for example by implementing integrated frameworks of social cohesion (see for example Markus, 2016). Furthermore, the establishment of an action research agenda might provide an answer to one major limitation of this study, namely that the research has investigated the immediate and momentary understandings of practitioners with regard to social cohesion, whilst learning from community activities can develop on a rather slow burn and can be contained in tacit and thus implicit knowledge.

Concretely, we believe that structurally aware community sport praxis does not suggest disposing entirely of dominant individualized approaches, such as casework 
(Goldsworthy, 2002). Rather, we urge the adoption of these individualized approaches as a way to augment the competency of community sport institutions to transcend these individual formats and transform it into a forum wherein tacit, individual knowledge can be deepened and broadened with a view to developing collective knowledge and wherein this collective frame of mind can, for example, provide a basis for sending out structural signals to community sport policy and practice.

\section{Funding statement}

This research project is subsidized by the Flemish Government.

\section{References}

Berger-Schmitt, R. (2000) 'Social cohesion as an aspect of the quality of societies: concept and measurements', EuReporting Working Paper No. 14, Centre for Survey Research and Methodology, Manheim.

Beutler, I. (2008) Sport serving development and peace: achieving the goals of the United Nations through sport, Sport in Society, 11 (4), 359-369.

Bourdieu, P. (1986) The forms of social capital, in J. Richardson, ed, Handbook of Theory and Research for the Sociology of Education, Greenwood Press, Westport, pp. 241-256.

Bramham, P. Hylton, K. Jackson, D and Nesti, M. (2001) Introduction, in K. Hylton, P. Bramham, F. Jackson and M. Nesti, eds, Sport Development: Policy, Process and Practice, Routledge, London, pp. 1-6.

Coakley, J. (2015) Assessing the sociology of sport: on cultural sensibilities and the great sport myth, International Review for the Sociology of Sport, 50 (4), 402-406.

Crabbe, T. (2009) Getting to know you: using sport to engage and build relationships with socially marginalized youth, in R. Levermore and A. Beacom, eds, Sport and International Development, Palgrave MacMillan, England, pp. 176-198.

Dale, A and Newman, L. (2008) Social capital: a necessary and sufficient condition for sustainable community Development? Community Development Journal, 45 (1), 5-21.

DiCicco-Bloom, B and Crabtree, B. F. (2006) The qualitative research interview, Medical Education, 40, 314-321.

Donnelly, J. (2015) Towards Gender Equality through Equity in Community-level Evaluation, Evaluation Journal of Australasia, 15 (1), 15-18. 
Ekholm, D. (2016) Sport as a means of responding to social problems, $\mathrm{PhD}$ Thesis, Linköping University, Sweden.

Glover, T. D and Hemingway, J. (2005) Locating leisure in the social capital literature, Journal of Leisure Research, 37 (4), 387-401.

Goldsworthy, J. (2002) Resurrecting a model of integrating individual work with community development and social action, Community Development Journal, 37 (4), 327-337.

Grodach, C. (2009) Art spaces, public space, and the link to community development, Community Development Journal, 45 (4), 474-493.

Haudenhuyse, R and Theeboom, M. (2015) Buurtsport en sociale innovatie: een tweede start voor buurtsport in Vlaanderen?, in M. Theeboom, R. Haudenhuyse and J. Vertonghen, eds, Sport en Sociale Innovatie, VUBPRESS, Brussels, pp. 191-208.

Hsieh, H. F and Shannon, S. A. (2005) Three approaches to qualitative content analysis, Qualitative Health Research, 15 (9), 1277-1288.

Kay, A. (2005) Social capital, the social economy and community development, Community Development Journal, 4 (2), 160-173.

Kearns, A and Forrest, R. (2000) Social cohesion and multilevel governance, Urban Studies, 37 (5/6), 995-1017.

Kelly, L. (2010) 'Social inclusion' through sports-based interventions? Critical Social Policy, 31 (1), 126-150.

Markus, A. (2016) Mapping social cohesion: the Scanlon Foundation surveys 2016, Monash University, Australia.

Markus, A. and Kirpitchenko, L. (2007) Conceptualising social cohesion, in J. Jupp, ed, Social Cohesion in Australia, Cambridge University Press, England, pp. 21-32.

Meir, D and Fletcher, T. (2017) The transformative potential of using participatory community sport initiatives to promote social cohesion in divided community contexts, International Review for the Sociology of Sport, 52 (5), 1-21.

O'Carroll, J. P. (2002) Culture lag and democratic deficit in Ireland: or, 'dat's outside de terms of d'agreement', Community Development Journal, 37 (1), 10-19.

Philips, D and Berman, Y. (2003) Social quality and ethnos communities: concepts and indicators, Community Development Journal, 38 (4), 344-357.

Province of West Flanders (2014). Kansarmoedeatlas West-Vlaanderen (Atlas of Poverty in West Flanders) Province of West Flanders, retrieved from: https://webshop.westvlaanderen.be. (26 July 2017). 
Putnam, R. (1993) Making Democracy Work: Civic Traditions in Modern Italy, Princeton University Press, Princeton.

Reeskens, T. (2008) 'Defining social cohesion in diverse societies: how generalized trust relates to social cohesion', Paper prepared for the Research Day of the Faculty of Social Sciences (Centre for Political Research), 27 October 2008, Leuven, Belgium.

Ruch, G. (2005) ‘Self-ish’ spaces: reflective practice and reflexivity in contemporary child care social work practice and research in the U.K., eds, in L. M. Stoneham, Advances in Sociology Research, Volume 2, Nova Science Pub Inc., England, pp. 165-192.

Sabirova, G and Zinoviev, A. (2016) Urban local sport clubs, migrant children and youth in Russia, Community Development Journal, 51 (4), 482-498.

Schulenkorf, N. (2010) Towards sustainable community development through sport and events: a conceptual framework for sport-for-development projects, Sport Management Review, $15(1), 1-12$.

Skinner, J. Zakus, D and Cowell, J. (2008) Development through sport: building social capital in disadvantaged communities, Sport Management Review, 11 (3), 253-275.

Smets, P. (2005) Living apart or together? Multiculturalism at a neighbourhood level, Community Development Journal, 41 (3), 293-306.

Spaaij, R. (2011) Sport and Social Mobility: Crossing Boundaries, Routledge, New York.

Spaaij, R. Magee, J and Jeanes, R. (2014) Sport and Social Exclusion in Global Society, Routledge, London.

Stead, V. (2017) Doing 'social cohesion': cultural policy and practice in outer metropolitan Melbourne, Critical Social Policy, 37 (3), 1-20.

Theeboom, M. Haudenhuyse, R and De Knop, P. (2010) Community sports development for socially deprived groups: a wider role for the commercial sports sector? A look at the Flemish situation, Sport in Society, 13 (9), 1392-1410.

Vandermeerschen, H. (2016) Being poor, being benched? Sports participation and opportunities for people in poverty: in search of an inclusive policy, $\mathrm{PhD}$ Thesis, University of Leuven, Belgium.

Westbrook, L. (1994) Qualitative research methods: a review of major stages, data analysis techniques, and quality controls, Information Science Research, 16 (3), 241-254. 